\title{
MESSAGE FROM THE COMMANDANT
}

Dear readers,

Nearly 12 years ago SBH entered in research and publication. Its 1st publication was released on 2056 It has been a long time since we thought of it, we could have been far ahead in the form of quality and standard of our Journal, unfortunately that has not happened, Presently for the last few years, after our association with NAMS our young colleagues have shown interest to participate in publication.

This hospital being a general hospital is very busy and earlier we had less manpower and more work. Lack of proper documentation of Great clinical work done by us couldn't be documented and shared with others. Now we have realized the importance of sharing our work and experiences through publications.

We all known writing article in Journal is an art, it has got its own norms and pattern to be followed, unless and until we follow the pattern and practice regularly we won't be able to write quality, worth reading publication.

I am glad that 2nd Issue of 10th edition is being published and likes to thank editorial board for their hard and sincere effort.

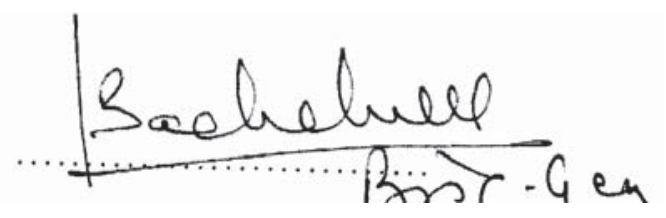

Brig.Gen.Prof. Dr. Bachhu Ram K.C.

M.S. (Ortho)

Commandant

Shree Birendra Hospital 